\title{
ASSESSING MUTAGENICITY OF TEXTILE DYES FROM PALI (RAJASTHAN) USING AMES BIOASSAY
}

\author{
N. MATHUR* - P. BHATNAGAR - P. BAKRE \\ *e-mail: nupurmathur123@rediffmail.com \\ Environmental Toxicology Unit, Department of Zoology, \\ University of Rajasthan, Jaipur 302004, India \\ *Corresponding author \\ (Received $6^{\text {th }}$ June 2005 , accepted $4^{\text {th }}$ August 2005)
}

\begin{abstract}
In Rajasthan state particularly, textile mills represent an important economic sector. Pali district in Rajasthan has got largest number of textile industries in the State i.e.989 units, mostly engaged in cotton and synthetic textile printing and dyeing. These industries liberate a variety of chemicals, dyes, acids and alkalis besides other toxic compounds like heavy metals, which are known for their hazardous properties. However, excessive and indiscriminate use of dyestuffs has become increasingly a subject of environmental concern. These dyes can enter the environment through the industrial effluents of dye manufacturing plants and from textile dyeing and printing operations, as wastewater effluents. Assessment of genotoxicity of dyes is therefore of utmost importance. Short-term genetic bioassays have proved to be an important tool in such studies because of their simplicity, sensitivity to genetic damage, speed, low cost of experimentation and small amount of sample required. A total of 7 dyes were tested for their mutagenicity, by Ames assay, using strain TA 100 of Salmonella typhimurium. Only 1 dye, Violet showed absence of mutagenic activity. The remaining 6 dyes were all positively mutagenic.
\end{abstract}

Keywords: Pali, textile industries, dyes, mutagenicity, Ames test

\section{Introduction}

India's dye industry produces every type of dyes and pigments. Production of dyestuff and pigments in India is close to 80,000 tonnes. India is the second largest exporter of dyestuffs and intermediates developing countries, after China. The textile industry accounts for the largest consumption of dyestuffs, at nearly $80 \%$.

The textile industries are to satisfy the ever-growing demands in terms of quality, variety, fastness and other technical requirements. However, a recent study conducted under the National Biodiversity strategy and Action Plan (BSAP) has revealed that chemical colors have all but wiped out India's wonderful vegetable dyes. The Indian textile industries now predominantly use synthetic organic dyes like direct dyes, processing dyes, reactive dyes, etc. The large variety of dyes and chemicals used in an attempt to make more attractive popular shades of fabrics for a competitive market render them very complex [16]. During the last decade, environmental issues associated with dyestuff production and application have grown significantly and are indisputably among the major driving forces affecting the textile dye industry today.

Pali is an important district of Rajasthan, having a population of 18,19, 201 people. It is situated about $70 \mathrm{kms}$ from Jodhpur. The district lies between $24^{\circ} 50^{\prime}$ and $26^{0} 75^{\prime}$ North Latitude and $72^{\circ} 48^{\prime}$ and $74^{\circ} 20^{\prime}$ East Longitude. It is situated on the banks of river Bandi. The total area of this town is about 12,387 Sq. kms. There are around 989 dyeing and printing units, most of which discharge their untreated textile effluents, directly into river Bandi.

Considerable amounts of dyes have been noticed in these textile wastewaters, due to their incomplete use and washing operations. The dyes disposed off, can be found in dissolved state or in suspension in the wastewater. These dyestuffs are highly structured 
polymers and are very difficult to decompose biologically [13]. The most obvious impact of the discharge of dye colored effluent is the persisting nature of the color. It is stable and fast, difficult to degrade, toxic, rendering the water unfit for its intended use. Further, the color removal is also not adequate by the conventional chemical and biological treatment. Such dyestuffs can reach the aquatic environment, primarily dissolved or suspended in water, since the conventional treatment of wastewaters from textile mills and dyestuff factories are unable to remove most of the azo and other dyes effectively. The resulting dye effluents may contain some components or moieties that could be toxic, carcinogenic or mutagenic to aquatic life [18]. Ecological and toxicological problems due to the discharge of textile wastewaters, in natural water bodies, have been one of the most important water pollution problems in the state of Rajasthan and especially in Pali.

Since large quantities of dyes are used, such pollution due to dyes may occur on a significant scale. The International Agency for Research on Cancer (IARC) has classified various dyes like Benzidine as being associated with cancer in humans [6]. Benzidine is known to be carcinogenic to a variety of mammalian species, including humans. In tests on laboratory animals, two benzidine dyes, Direct Blue 6 and Direct Black 38, have been reported to be such potent carcinogens that hepatocellular carcinomas and neoplastic liver nodules occurred in rats after only 13 weeks of exposure [17]. A number of dyes have been tested for mutagenicity using Salmonella assay. Several of them have been found to be carcinogenic $[4,15,19]$.

Because of the wide spread use and potential carcinogenicity of certain dyes, there has been a growing interest in assessing the hazards associated with dyes available in local markets. Most of such dyes, being openly sold in the markets have no information regarding their chemical nature, purity, toxicity or possible mutagenicity. Unlimited and uncontrolled use of such dyes can lead to grave consequences in terms of human health and ecological balance Central Pollution Control Board has listed the dye and dye intermediates industry as one of the heavily polluting industries. Assessment of genotoxicity of dyes is therefore of utmost importance.

Various short-term screening methods have been developed to detect mutagenic/carcinogenic substances. They have played important roles not only in screening suspected chemicals but also in studying the mechanisms of mutagenesis and carcinogenesis, and have provided useful information for assessing the genetic effects of chemicals on humans.

Microorganisms have demonstrated several attributes that make them attractive for use in quick screening of effluents and chemicals for toxicity. Testing of chemicals for mutagenicity in Ames assay is based on the knowledge that a substance that is mutagenic in the bacterium is likely to be a carcinogen in laboratory animals, and thus, by extension, present a risk of cancer to humans. The Ames test has several advantages over the use of mammals for testing compounds. Mutagenicity assays are relatively cost effective, only a few days are required for testing a compound and the test is performed with microgram quantities of the material. Such assays are performed on approximately 100 million organisms rather than on a limited number of animals.

The present study is thus aimed at studying the mutagenic potential of the locally available and used textile dyes. Most of these dyes have not been characterized regarding their chemical nature, purity, possible toxicity or their impact on health and the environment. Assessment of genotoxicity of dyes is therefore of utmost importance. 


\section{Materials and methods}

\section{Collection of samples}

Dyes (18) were obtained at random basis from local Pali market. They had no information regarding chemical constituents, purity or hazardous nature. Dye solutions were made by dissolving $1 \mathrm{~g}$ dry powder of dye in $100 \mathrm{ml}$ of warm, sterile, distilled water. All the dyes used were water-soluble. Five concentrations $(2 \mu 1,5 \mu 1,10 \mu 1,50 \mu 1$ and $100 \mu \mathrm{l})$ of these dyes were tested.

\section{Ames mutagenicity test}

The Salmonella/microsome reversion assay was conducted using the plate incorporation procedure described by Ames et al. [1] and revised by Maron and Ames [8]. The dye samples were tested with TA 100 strain of S. typhimurium, which was obtained from Microbial Type culture collection \& Gene Bank (MTCC), Institute of Microbial Technology (IMTech), Chandigarh (INDIA). Samples were tested on duplicate plates in two independent experiments. Five dose levels of individual samples were tested. Positive control used for TA 100 was Sodium azide (CAS Number: 2662822-8): $5 \mu \mathrm{g} /$ plate: 2969 revertants. Sterile distilled water was used as negative control. Fresh solutions of the reference mutagen were prepared immediately before the beginning of each experiment. The revertant colonies were clearly visible in a uniform background lawn of auxotrophic bacteria. All tester strains were maintained and stored according to the standard methods [12]. The tester strain genotypes (Histidine requirement, $r f a$ mutation, $u v r \mathrm{~B}$ and $\mathrm{R}$-factor) were confirmed immediately after receiving the cultures and every time a new set of frozen permanents were prepared or used. All regents used were of analytical grade, supplied by Himedia Laboratories Limited (India) and Sigma-Aldrich.

\section{Data analysis}

The most common method of evaluation of data from the Salmonella assay is the "two fold rule" according to which doubling of spontaneous reversion rate at one or two test chemical concentrations constitutes a positive response [12]. This rule specifies that if a test compound doubles or more than doubles, the mean spontaneous mutation frequency obtained on the day of testing, then the compound is considered significantly mutagenic. Using this procedure the following criteria were used to interpret results:

\section{Positive}

A compound is considered a mutagen if it produces a reproducible, dose-related increase in the number of revertant colonies in one or more strains of Salmonella typhimurium. A compound is considered a weak mutagen if it produces a reproducible dose-related increase in the number of revertant colonies in one or more strains but the number of revertants is not double the background number of colonies.

Negative

A compound is considered a non-mutagen if no dose-related increase in the number of revertant colonies is observed in at least two independent experiments.

\section{Inconclusive}

If a compound cannot be identified clearly as a mutagen or a non-mutagen, the results are classified as inconclusive (e.g. if there is one elevated count).

For this analysis the dose related increases in the number of revertant colonies were observed for the test compounds and mutagenicity ratios were calculated. Mutagenicity 
ratio is the ratio of average induced revertants on test plates (spontaneous revertants plus induced revertants) to average spontaneous revertants on negative control plates (spontaneous revertants). Mutagenicity ratio of 2.0 or more is regarded as a significant indication of mutagenicity

\section{Results and Discussion}

Pali has been identified as one of the most polluted cities in India [3]. The grave pollution situation that exists in and around Pali due to the textile industries has been extensively studied $[5,7,9]$. Further, increasing trend of requirement and productivity of dyes and dye intermediates is associated with the anticipated generation of wastes, both liquid and solid in future. The wastes thus produced will contain toxic and hazardous substances, which are not acceptable to the recipient environment, if released uncontrolled [9].

Many of the dyes used by textile industries are known carcinogens [6] and teratogens [2]. Dyes are introduced into the environment through industrial effluents of these industries. There are ample evidences of their harmful effects. Triple primary cancers involving kidney, urinary bladder and liver in a dye worker have been reported [11]. Further, Pal and Brijmohan [14] reported that textile industry poses threat of various types of occupational diseases.

A total of seven dyes were tested in the present study. Three of these were Processing dyes or Cremazoles (Orange 3R, Brown GR and Blue S1) while remaining four were Direct dyes (Violet, Congo red, Royal blue and Bordeaux). Amongst the four direct dyes only one dye i.e. Violet had Mutagenicity ratio less than 2.0 at all concentrations tested (Table 1). Further no dose related increase in number of revertant colonies was observed.

The dose response curves of all the dyes are shown in Fig. 1. Both Congo red and Royal blue dyes were positively mutagenic and can be classified as moderately mutagenic (700-1200 induced revertants, per $100 \mu 1$ of dye) (Fig. 1). Compared to the previously mentioned dyes Bordeaux showed higher number of revertants and can be classified as highly mutagenic or extremely mutagenic $(12,000$ induced revertants, per $100 \mu 1$ of dye) (Fig. 1). These observations are in accordance with several studies that report mutagenicity of a number of dyes like Direct Black 38, Acid Red 26, etc. [4, 19]. Unlimited and uncontrolled use of such dyes can lead to grave consequences in terms of human health and ecological balance.

Further all the three tested Processing dyes or Cremazoles dyes were so toxic that they inhibited the growth of bacteria, at higher dose levels. Again although Orange 3R and Brown GR were moderately mutagenic (1200-1400 induced revertants, per $100 \mu \mathrm{l}$ of dye) while Blue S1 turned out to be extremely mutagenic $(15,000$ induced revertants, per $100 \mu 1$ of dye) (Fig. 1). Strain TA 100 of Salmonella typhimurium, detects base pair substitution mutations. Thus, it can be concluded that all of these six dyes cause genetic damage through base pair substitution mutations.

Most of the dyes, used in textile industry are known only by their trade name, while their chemical nature and biological hazards are not known. The aim of this study was, thus, to assess the possible risk of mutagenic hazard due to these dyes and the effluents containing these dyes, to health of textile dyeing workers and the environment. The dyes were used in their crude form and no further purification was attempted, because we wanted to test the potential danger that they represent in actual use. The results of 
this study clearly indicate that most of the locally used dyes are highly mutagenic, and therefore should be used with great caution.

Table 1. Absorbance maximum and mutagenicity ratio of dyes $(1 \mathrm{~g} / 100 \mathrm{ml})$ with strain TA 100 of Salmonella typhimurium

\begin{tabular}{|c|c|c|c|c|c|c|c|c|}
\hline \multirow{2}{*}{ S. n. } & \multirow{2}{*}{ Dyes } & \multirow{2}{*}{ Peak } & \multirow{2}{*}{$\begin{array}{l}\text { Absor- } \\
\text { bance }\end{array}$} & \multicolumn{5}{|c|}{ Mutagenicity ratio } \\
\hline & & & & $2 \mu \mathrm{I}$ & $5 \mu \mathrm{l}$ & $10 \mu \mathrm{l}$ & $50 \mu \mathrm{I}$ & $100 \mu \mathrm{I}$ \\
\hline 1 & Orange 3R & 490.0 & 0.7791 & 0.7 & 1.1 & 7.2 & 3.4 & 2.5 \\
\hline 2 & Brown GR & 454.5 & 1.1201 & 1.7 & 2.1 & 9.2 & 4.4 & 3.5 \\
\hline 3 & Blue S1 & 594.5 & 2.1387 & 61.9 & 74.2 & 92.4 & 73.7 & 7.4 \\
\hline 4 & Violet & 536.0 & 2.1106 & - & - & - & - & - \\
\hline 5 & Congo Red & 485.5 & 0.9250 & - & 0.8 & 1.7 & 2.6 & 3.5 \\
\hline 6 & Royal Blue & 581.5 & 0.9929 & - & 0.4 & 2.6 & 3.0 & 5.8 \\
\hline 7 & Bordeaux & 512.5 & 1.0613 & 8.4 & 10.0 & 11.8 & 15.0 & 17.1 \\
\hline
\end{tabular}

The dyes were identified with the help of their absorption spectrums and absorbance peaks or maxima (Fig.2). The presence of impurities in the commercially available dyes has been reported to contribute to the mutagenicity of these dyes [15]. As the dyes under investigation were not purified, the impurities present in them could have also been responsible for the high mutagenic activity of the dyes. Nevertheless, the fact still remains that highly mutagenic compounds are being used in textile dyeing and printing industries of Pali.
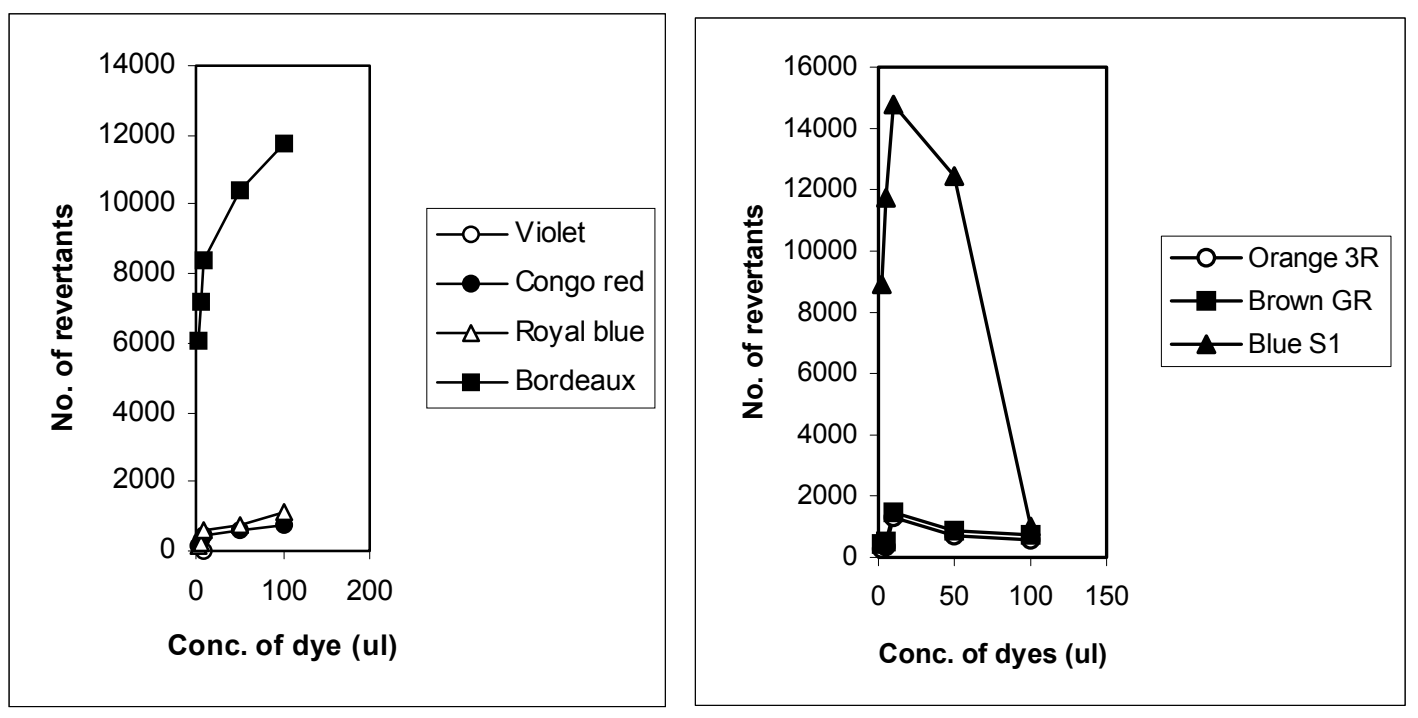

Figure 1. Dose response curve of dyes with strain TA 100 of Salmonella typhimurium

Since innumerable dyes are available in local markets, chemical analysis of each and every dye is not possible because of the time and cost involved. As the bacterial mutagenicity assays can be carried out in $48 \mathrm{hrs}$, they have been suggested as rapid prescreens for distinguishing between carcinogenic and non-carcinogenic chemicals, allowing many thousands of compounds in our environment, not previously tested, to be screened for potential hazard. A good co-relation has been obtained by several groups, for a number of carcinogenic aromatic amines in their ability to induce mutation in the 
above strain and the ability to induce a response in animals. Thus Ames test can easily and quickly assess mutagenic potential of these dyes.
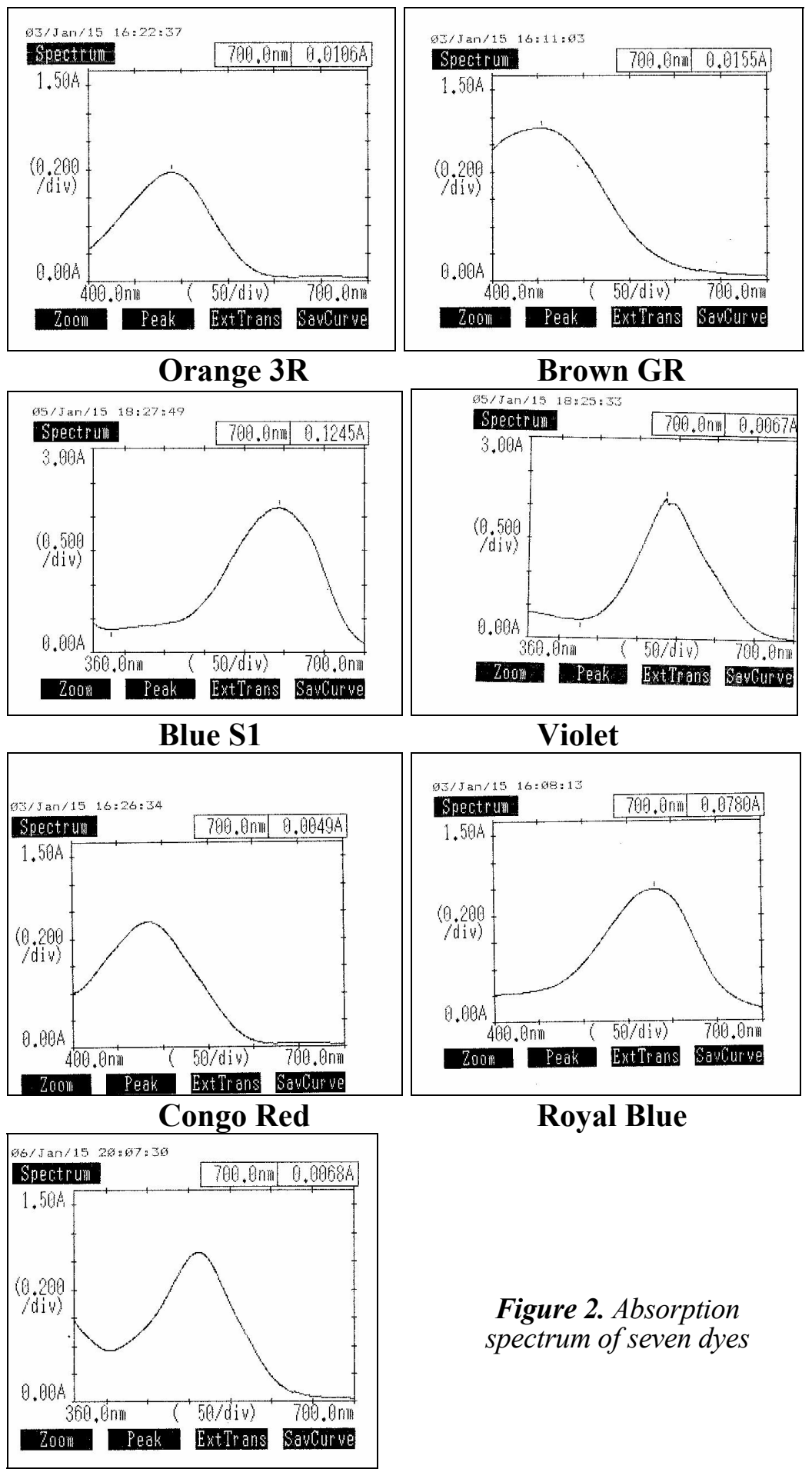

\section{Royal Blue}

Figure 2. Absorption spectrum of seven dyes

Besides, the dyes can be compared on the basis of their mutagenic potencies. This bioassay can thus be used as an initial screening test to analyze various dyes and dye containing effluents, which are causing major damage to the aquatic environment. 
Further, excessive use of synthetic chemical dyes should be restricted. They should be replaced by vegetable dyes, which are eco-friendly.

Acknowledgements. The authors are thankful to Dr. P. Ghosh, Director and Dr. Krishnamohan, Senior scientist, Birla Institute of Scientific Research, Jaipur (India) for allowing the use of various facilities of the Biotechnology division

\section{REFERENCES}

[1] Ames, B.N., McCann, J. and Yamasaki, E. (1975): Methods for detecting carcinogens and mutagens with the Salmonella/mammalian microsome mutagenicity test. - Mut. Res.,3: 347-364.

[2] Beck, S.L. (1983): Assessment of adult skeletons to detect prenatal exposure to Trypan Blue in mice. - Teratology, 28: 271-285.

[3] Chhoakar, P.K., Datta, S.P., Joshi, H.C. and Pathak, H. (2000): Impact of industrial effluents on soil health and agriculture-Indian experience: Part-II tannery and textile industrial effluents. - J. Scientific and Industrial research, 59: 446-454.

[4] Garner, R.C. and Nutman, C.A. (1977): Testing of some azo dyes and their reduction products for mutagenicity using Salmonella typhimurium TA 1538. - Mut. Res., 44: 919.

[5] Gupta, S.C. (1992): Industrialization and chemical hazards. Swasth Hindof ground waters polluted due to textile hand processing industries in Pali. - Curr. Agric., 16 (1-2): 59-62.

[6] Anonym - International Agency for Research on Cancer, Suppl. 4 (1982): IARC Monographs on the evaluation of the carcinogenic risk of chemicals to humans, chemicals, industrial processes and industries associated with cancer in humans, IARC, Lyon.

[7] Khandelwal, S. (1996): Impact of dyeing industries, wastewater on vegetation of Luni catchment area: A case study through remote sensing technique. - J. Environ. Poll., 3 (2): 77-78.

[8] Maron D.M. and Ames B.N. (1983): Revised methods for the Salmonella mutagenicity test. - Mut. Res., 113: 173-215.

[9] Mohnot, S.M. and Dugar, S. (1987): Textile industry and water pollution problem of Western Rajasthan. Environmental degradation of Western Rajasthan, - in: S.M. Mohnot and M.M. Bhandari (Eds.): 63-71.

[10] Mohnot, S.M. and Durve, V.S. (1989): Evaluation of the Hazards of untreated and treated textile dyeing and printing waste on mammals. - Technical report VIII=61.Man and Biosphere Program. Govt. of India. New Delhi.

[11] Morikawa, Y.,K. Shiomi, Y.Ishihara and N. Matsuura(1997):Triple primary cancers involving Kidney, Urinary Bladder and Liver in a dye workers. - Am. J. of Indus. Med., 31, 44-49).

[12] Mortelmans, K. and Zeiger, E.(2000):The Ames Salmonella /microsome mutagenicity assay. - Mut. Res., 455: 29-60.

[13] Neppolian, B., Sakthivel, S., Arbindo, B., Palanichamy, M. and Murugesan, V. (1999): Degradation of textile dye by solar light using $\mathrm{TiO}_{2}$ and $\mathrm{ZnO}$ photocatalyst. - J. Environ. Sci. health, A 34 (9): 1829-1838.

[14] Pal, P.B. and Brijmohan (1980): Management of occupational environment in textile industry. - Indian J. Environ. Prot., 10 (10): 767-772.

[15] Prival, M.J., S.J. Bell, V.D. Mitchell and V.L. Vaughan: Mutagenicity of benzidine and benzidine congener dyes and selected monoazo dyes in a modified Salmonella assay. Mut. Res., 136: 33-47. 
[16] Rajagopalan, S. (1990): Water pollution problem in Textile Industry and Control, in: Pollution Management in Industries R.K.Trivedy (Ed.), - Environmental Pollution, Karad, India pp 21-45.

[17] Robens, J.F., Dill, G.S., Ward, J.M. Joiner, J.R., Griesemer R.A. and Douglas, J.F. (1980): Thirteen-week subchronic toxicity studies of Direct Blue 6, Direct Black 38 and Direct Brown 95 dyes. - Toxicol. Appl. Pharmacol., 54 : 431-442.

[18] Suzuki, T., Timofei, S., Kurunczi, L., Dietze, U. and Schuurmann, G. (2001): Correlation of aerobic biodegradability of sulfonated azo dyes with the chemical structure. Chemosphere, $45: 1-9$.

[19] Venturini, S. and Tamaro, M. (1979): Mutagencity of anthraquinone and azo dyes in Ames Salmonella typhimurium test. - Mut. Res., 68: 307-312. 